\title{
Can Hong Kong take advantage of recent advances in allergy prevention?
}

\author{
TH Lee ${ }^{1}$ *, ScD, FRCP, HK Ho ${ }^{2}$, MD, FRCPCH, TF Leung ${ }^{3}$, MD, FRCPCH \\ ${ }^{1}$ Allergy Centre, Hong Kong Sanatorium \& Hospital, Happy Valley, Hong Kong \\ ${ }^{2}$ Department of Paediatrics and Adolescent Medicine, Queen Mary Hospital, The University of Hong Kong, Pokfulam, Hong Kong \\ ${ }^{3}$ Department of Paediatrics, Prince of Wales Hospital, The Chinese University of Hong Kong, Shatin, Hong Kong \\ *Corresponding author: takhong.lee@hksh.com
}

Hong Kong Med J 2017;23:539-40

DOI: 10.12809/hkmj175069

\section{Introduction}

Major opportunities have been identified recently to prevent allergic disorders including the early introduction of allergenic foods to infants ${ }^{1-9}$ and immunotherapy. ${ }^{10,11}$ Breast feeding is still strongly encouraged, but new evidence suggests that the avoidance of allergenic foods in infancy to delay the onset of allergic diseases may have sustained rather than prevented food allergies and eczema. International guidelines on infant feeding are being revised. ${ }^{12-14}$ It is a moot point whether Hong Kong has the infrastructure required to exploit these transformative opportunities to improve public health in allergy.

\section{Can Hong Kong take advantage of the recent} advances in allergy prevention?

In 2014, it was estimated that Hong Kong had only one allergy specialist for 1.5 million people, ${ }^{15}$ and there had been no local trainees in immunology and allergy in adult medicine for nearly two decades. The current ratio of registered adult allergists per head of population in Hong Kong remains approximately one per 2.8 million, one of the lowest in the world. ${ }^{15}$ There are 2.4 full-time equivalent specialists in paediatric allergy, about one paediatric allergist per 540000 paediatric population. This is less than the previous estimate 3 years ago of 1:460000. ${ }^{15}$ The situation should improve by the end of 2017 when two trainees complete their training in Paediatric Immunology and Infectious Diseases (PIID). Nonetheless these graduates will only work parttime in allergy because of the manpower constraints in the public hospital system. Hong Kong also has two clinical immunologists who work part-time. Therefore, by the end of 2017 it is estimated that Hong Kong will have one allergist per 1.17 million population, a slight improvement on the $1: 1.5$ million figure estimated for 2014 although the ratio is still very low.

One way to grow a discipline is to recruit specialists from overseas. ${ }^{1}$ In 2016, a public hospital recruited a paediatrician who had already completed his medical, paediatric, and allergy/immunology training in the United States. Nonetheless he is now required to spend a further 4 to 5 more years fulfilling the requirements of the Medical Registration Ordinance and specialty registration before he is recognised as a PIID specialist in Hong Kong. Whether it is desirable to have a more expeditious mechanism to assimilate doctors trained overseas, especially those with expertise that can fulfil an unmet need, into the local health care system is a subject of intense current debate. ${ }^{16,17}$

Another way to create more allergy services in public hospitals is by realigning resources. ${ }^{15}$ Two public hospitals have adopted this strategy and now each offers a new penicillin allergy testing service. The new services are operated by a respiratory medicine specialist and a trainee allergist under supervision. Both clinicians gained experience in testing for drug allergies at an allergy centre in a local private hospital under the supervision of a specialist who is included in the 'Immunology and Allergy' Registry (S34) of the Medical Council of Hong Kong (MCHK). This example of collaboration between the private and public sectors could provide a template for future progress.

\section{Training}

A robust throughput of trainees is essential to grow a specialty. In a long overdue development, Hong Kong now has its first trainee in adult allergy (MCHK Specialist Registration S34) in 20 years. This trainee, however, has to spend time training overseas as there is no locally available adult allergy trainer. Allergy specialists in private practice are not recognised by the Hong Kong College of Physicians (HKCP) as official trainers because they do not work in a HKCP-recognised training centre. There are undoubted benefits of gaining experience overseas but consideration could be given to improving the training environment in Hong Kong. A structured pathway could be developed to maximise the local opportunities to train future specialists.

There has been a successful training programme for paediatric allergists for several years. The subspecialty board of PIID (S56) under the Hong Kong College of Paediatricians has recently applied 
to change its name to 'Paediatric Immunology, Allergy and Infectious Diseases' (PIAID). This is a major step forward for the future of paediatric allergy as a discipline in Hong Kong and may attract additional trainees.

\section{Professional societies and patient organisations}

The community is well-supported by allergy-related professional societies and patient organisations. These include the Hong Kong Institute of Allergy (HKIA), Hong Kong Society of Paediatric Respirology and Allergy, Hong Kong Society for Paediatric Immunology and Infectious Diseases, The Hong Kong Allergy Association (HKAA), and The Hong Kong Asthma Society (HKAS). To a certain extent they all host allergy conventions, symposia, and courses. Scientific papers ${ }^{18-20}$ and clinical allergy practice guidelines ${ }^{1}$ are published. Some of them have social media platforms to engage the public, have their own websites, and publish regular newsletters. The HKIA also offers educational scholarships and research grants. The two patient organisations, namely HKAA and HKAS, are committed to making a difference to patient experience through peer-group support, patient and public education, advocacy, and organisation of social activities.

\section{Conclusions}

Patients with allergic diseases in Hong Kong are well-served by professional societies and patient organisations but there remains inadequate clinical support to take full advantage of recent major public health advances in allergy. It is recommended again that centres of excellence in allergy be established to drive patient care and teaching of under- and postgraduate students, and to conduct world-leading research in the discipline. ${ }^{15}$

Each of the two medical schools with their partner hospitals in Hong Kong has the core of an allergy and immunology service already. It would not require large resources to transform them into centres of excellence. The imminent opening of the Hong Kong Children's Hospital also provides an opportunity to synergise various strands of paediatric allergy and immunology expertise. If the vision for the creation of allergy centres can be realised, Hong Kong can play its part in stemming the global allergy epidemic for the benefit of its community.

\section{References}

1. Chan AW, Chan JK, Tam AY, Leung TF, Lee TH. Guidelines for allergy prevention in Hong Kong. Hong Kong Med J 2016;22:279-85.

2. von Berg A, Filipiak-Pittroff B, Schulz H, et al. Allergic manifestation 15 years after early intervention with hydrolyzed formulas - the GINI Study. Allergy 2016;71:210-9.

3. de Silva D, Geromi M, Halken S, et al. Primary prevention of food allergy in children and adults: systematic review. Allergy 2014;69: 581-9.

4. Grimshaw KE, Maskell J, Oliver EM, et al. Diet and food allergy development during infancy: birth cohort study findings using prospective food diary data. J Allergy Clin Immunol 2014;133:511-9.

5. Nwaru BI, Erkkola $\mathrm{M}$, Ahonen $\mathrm{S}$, et al. Age at the introduction of solid foods during the first year and allergic sensitization at age 5 years. Pediatrics 2010;125:50-9.

6. Du Toit G, Roberts G, Sayre PH, et al. Randomized trial of peanut consumption in infants at risk for peanut allergy. $\mathrm{N}$ Engl J Med 2015;372:803-13.

7. Perkin MR, Logan K, Tseng A et al. Randomized trial of introduction of allergenic foods in breast-fed infants. $\mathrm{N}$ Engl J Med 2016;374:1733-43.

8. Palmer DJ, Sullivan TR, Gold MS, Prescott SL, Makrides M. Randomized controlled trial of early regular egg intake to prevent egg allergy. J Allergy Clin Immunol 2017;139:16007.e2.

9. Koplin JJ, Osborne NJ, Wake M, et al. Can early introduction of egg prevent egg allergy in infants? A population-based study. J Allergy Clin Immunol 2010;126:807-13.

10. Jacobsen L, Niggemann B, Dreborg S, et al. Specific immunotherapy has long-term preventive effect of seasonal and perennial asthma: 10-year follow-up on the PAT study. Allergy 2007;62:943-8.

11. Marogna M, Spadolini I, Massolo A, Canonica GW, Passalacqua G. Long-lasting effects of sublingual immunotherapy according to its duration: a 15 year prospective study. J Allergy Clin Immunol 2010;126:969-75.

12. Schäfer T, Bauer CP, Beyer K, et al. S3-Guideline on allergy prevention 2014 update: Guideline of the German Society for Allergology and Clinical Immunology (DGAKI) and the German Society for Pediatric and Adolescent Medicine (DGKJ). Allergo J Int 2014;23:186-99.

13. Fewtrell M, Bronsky J, Campoy C, et al. Complementary feeding: a position paper by the European Society for Paediatric Gastroenterology, Hepatology, and Nutrition (ESPGHAN) Committee on Nutrition. J Pediatr Gastroenterol Nutr 2017;64:119-32.

14. Togias A, Cooper SF, Acebal ML, et al. Addendum guidelines for the prevention of peanut allergy in the United States: Report of the National Institute of Allergy and Infectious Diseases-sponsored expert panel. J Allergy Clin Immunol 2017;139:29-44.

15. Chan YT, Ho HK, Lai CK, et al. Allergy in Hong Kong: an unmet need in service provision and training. Hong Kong Med J 2015;21:52-60.

16. LCQ9: Non-locally trained doctors practising in Hong Kong. Available from http://www.info.gov.hk/gia/general/ 201601/20/P201601200538.htm. Accessed 8 Jun 2017.

17. Lo A. Hong Kong needs to open the door to foreign doctors. South China Morning Post. 18 Jan 2017. Available from: http://www.scmp.com/comment/insight-opinion/ article/2062950/hong-kong-needs-open-door-foreigndoctors. Accessed 9 Jun 2017.

18. Lee TH, Chan J, Lau VW, Lee WL, Lau PC, Lo MH. Immunotherapy for peanut allergy. Hong Kong Med J 2014;20:325-30

19. Lee TH, Ho HK, Leung TF. Genetically modified foods and allergy. Hong Kong Med J 2017;23:291-5.

20. Lee TH, Wu YY, Chan JK, Ho HK, Li PH, Rosa Duque JS; for the Hong Kong Institute of Allergy. Immunoglobulin $\mathrm{G}$ testing in the diagnosis of food allergy and intolerance. Hong Kong Med J 2017;23:419-20. 